\title{
Comparison of Structural Capacity of Hot Mix Asphalt (HMA) Pavement Designs (AASHTO \& TRL RN-31)
}

\author{
W.K.Mampearachchi and T.Janaraj
}

\begin{abstract}
The primary objective of this research is to identify the proper design guidelines in terms of structural capacity, which enables to last longer life span without any major failure. Inducing very high stress on pavement is one of the major reasons for structural failure.
\end{abstract}

American Association of State Highway and Testing Officials (AASHTO) and the Transport Research Laboratory Road Note 31 (TRL RN-31) are the widely used pavement design guidelines by many road agencies. Hence, this study intends to compare and contrast AASHTO (1994) and TRL RN-31. AASHTO method involve with the complicated empirical equation 3 in appendix which has to be solved by iteration method to obtain the required structural capacity for given conditions. So, computer program was developed using JAVA to solve AASHTO equation. RN-31 and AASHTO methods have been directly compared for a range of subgrade California Bearing Ratio (CBR) and traffic levels.

Model pavements were constructed to evaluate the performance of the pavement for static load and field collected data were used to verify the Finite Element Model (FEM). The verified models were used to evaluate the structural performance of pavements. The main advantage of this review on flexible pavement design guidelines is that the pavement which provide higher structural capacity can be simply identified and constructed, so that, it can reduce the overall cost and provide good platform to the users.

Keywords: $\quad$ AASHTO, RN-31, Finite element modeling, Pavement strength.

\section{Introduction}

Flexible pavements are so named because the total pavement structure deflects, or flexes, under loading. A flexible pavement structure is typically composed of several layers of material. Each layer receives the loads from the above layer, spreads them out, and then passes on these loads to the next layer below. Thus, the further down in the pavement structure a particular layer is located the fewer loads (in terms of force per area) it must carry.

In order to take maximum advantage of this load spreading mechanism, material layers are usually arranged in the descending order of load bearing capacity with the highest load bearing capacity material which is most expensive, on the top and the lowest load bearing capacity material which is the least expensive, on the bottom. A typical flexible pavement structure consists of Asphalt, Base course and Subbase course.
RN-31[15, 16] does not make provision for new material in their design catalogue but AASHTO method is more flexible to designer. So flexibility on selecting material [14] in design guidelines is so important since it is economical to use the available material for road construction. [20].

\section{Background}

AASHTO method is the one which is widely used by most of the road agencies to design pavements. However road development agencies in most of the tropical countries use Transport Research Laboratory (U.K) Road Note 31(TRL RN-31). The design of heavy

Eng. Dr. W. K. Mampearachchi, PhD(Florida), B.Sc.
Eng. (Hons) (Moratuwa), MSCE(South Florida), CMILT
(UK).,Senior Lecturer, Department of Civil
Engineering, University of Moratuwa, Katubedda,
Moratuwa, Sri Lanka wasanthak@civil.mrt.ac.lk
T.Janaraj. B.Sc Eng.(Hons) (Moratuwa), PhD student,
School of Urban Development, Built Environment and
Engineering, Queensland University of Technology,
Queensland, Australia.


volume roads are based on AASHTO due to some limitation of RN 31 design guidelines.

The condition of the road network is vital importance to the economy of any country [18]. The early failure of road is predominantly by fatigue (crack) and rutting, which may limit serviceability [11]. Both of these failures are the important design criteria used in the mechanistic pavement design. Bending Stresses at the bottom of the asphalt layer and axial stresses at the subgrade level, control the fatigue and rutting stresses respectively $[3,5]$. However, recent studies dealing with the improvement of design methods of flexible pavements have pointed out that in most cases, when the bearing capacity of the soil is sufficient, this rutting takes place mainly in the granular base and subbase layers [4]. Moreover, fatigue (cracking) failure of the asphalt generally appears much later, when significant rutting has already developed [3]. So rutting failure is the main criteria that need to be carefully analyzed at initial stage in comparison of two guidelines.

For any given pavement attributes, the axle load, axle configuration, suspension type and tire inflation pressure will all affect the magnitude and distribution of stresses, strains and displacements in its structure [13]. Pavement fracture defects occur because of traffic loading, environmental effects or construction inadequacies. Cracking that only occurs in the wheel path is considered to be due to the influence of traffic loading, while cracking observed outside the wheel path, across the full width of the pavement is considered to be due to environmental factors [17].

If a design provides substantially lower thicknesses certainly increases the vertical stresses and maintenance cost, since the road will wear out at a fairly rapid rate. However, if the designer chooses to increase the initial cost by building a substantially stronger pavement, the maintenance cost decrease accordingly [19]. Cumulative vertical strain on the paving layer and the subgrade produce the deformation that results in rutting [10]. So these circumstances emphasize that Proper design guideline is required to eliminate early failure of the road, and to reduce the maintenance cost due to subsequent failures. So the need of a research to evaluate the performance of pavement designs available in design guidelines is vital.

\section{Relation between structural capacity and Equivalent Static Axle load \\ (ESALs)}

A computer software program has been developed to solve the empirical equation (Appendix, AASHTO [2]) used to calculate the Structural Number (SN). By using the software that was developed, AASHTO pavement's individual layer's structural numbers were calculated [2, 7]. Using Eq-1 given below, SN can be converted into layer thickness.

$$
\begin{aligned}
\mathrm{SN}_{3} & =\mathrm{a}_{1} \times \mathrm{D}_{1}+\mathrm{a}_{2} \times \mathrm{m}_{2} \times \mathrm{D}_{2}+\mathrm{a}_{3} \times \mathrm{m}_{3} \times \mathrm{D}_{3} \\
\mathrm{SN}_{\mathrm{i}} & =\text { Total structural number } \\
\mathrm{a}_{\mathrm{i}} & =\text { Material coefficient } \\
\mathrm{m}_{\mathrm{i}} & =\text { Drainage coefficient } \\
\mathrm{D}_{\mathrm{i}} & =\text { Individual layer thickness } \\
\mathrm{i} & =\text { Layer number }(\mathrm{i}=1,2,3 \ldots)
\end{aligned}
$$

AASHTO design requires higher asphalt thickness compared with the RN-31 which substantially increase the initial cost of the pavement. Serviceability, standard deviation and reliability factor are the ones which determine the functional classification of the road. Local road have the lowest reliability $(50 \%)$ in the functional classification. The study was focused on pavement design of local roads since low asphalt thickness is used in tropical countries as given in $\mathrm{RN} 31$. The value of

Table 1- AASHTO parameters

\begin{tabular}{|c|c|c|c|c|}
\hline Layers & $\begin{array}{l}\text { Material } \\
\text { Coeff. }\end{array}$ & value & $\begin{array}{l}\text { Drainage } \\
\text { Coeff. }\end{array}$ & value \\
\hline Asphalt & $\mathrm{a}_{1}$ & 0.32 & & \\
\hline Base & $\mathrm{a}_{2}$ & 0.17 & $\mathrm{~m}_{2}$ & 1.2 \\
\hline Subbase & $\mathrm{a}_{3}$ & 0.12 & $\mathrm{~m}_{3}$ & 0.8 \\
\hline Capping & $\mathrm{a}_{4}$ & 0.07 & $\mathrm{~m}_{4}$ & 0.4 \\
\hline
\end{tabular}

$$
\begin{array}{ll}
\text { Serviceability Index }(\Delta \mathrm{psi}) & =2.0 \\
\text { Standard deviation }\left(\mathrm{S}_{0}\right) & =0.42 \\
\text { Reliability }(\mathrm{R}=92 \%) \mathrm{Z}_{\mathrm{R}} & =-1.405
\end{array}
$$

serviceability index, standard deviation and reliability factor was selected based on the above assumption. Layer coefficients in AASHTO method and other required data values are tabulated in table 1.

In RN-31 [15, 16], individual layer thicknesses of the pavement design are available in the 
form of catalogue. Those pavement thicknesses were converted into structural number using individual layer coefficients in order to directly compare both methods in the form of structural number.

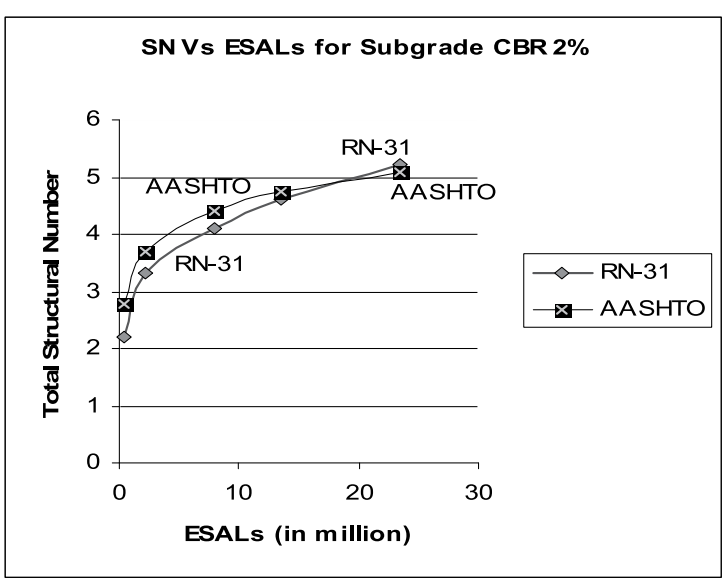

Figure 1 - SN Vs ESALs for Subgrade CBR-2\%

Fig. 1 shows the total Structural Number variation with ESALs for both design guidelines for Subgrade CBR of $2 \%$. SN difference of RN-31 and AASHTO (RN31 AASHTO) is plotted against ESALs for different subgrade CBR as shown in Fig. 2.
Fig. 2 clearly indicate that,

I. The gradients of all the graphs are the same

II. for all CBR values which indicates that the $\mathrm{SN}$ difference is proportional to ESALs.

III.Generally, higher $\mathrm{SN}$ is required at lower CBR to compensate lower subgrade support. Fig. 2 shows that RN 31 requires lower $\mathrm{SN}$ at lower CBR (negative value) compared with corresponding AASHTO design.

IV.Similarly, higher $\mathrm{SN}$ is required at higher ESAL to resist the cumulative damage due to repetitive load. It can be seen that RN 31 requires higher $\mathrm{SN}$ number compared with corresponding AASHTO design.

V. SN difference is about \pm 0.5 up to 5 million ESAL for all the subgrade categories.

\section{Effect of ESAL category on Base and asphalt layer thickness}

Fig. 3 shows the asphalt and base thickness variation with ESAL category for a selected CBR. ESALs range of 1.5-3.0, 6.0-10 and 17-30 million were selected to represent the low, medium and higher ESAL categories. (RN 31 can be used up to 30 million ESALs.) Further, it has been shown in the analysis of pavement design guidelines that the Asphalt and Base layer thicknesses are not affected by subgrade CBR.

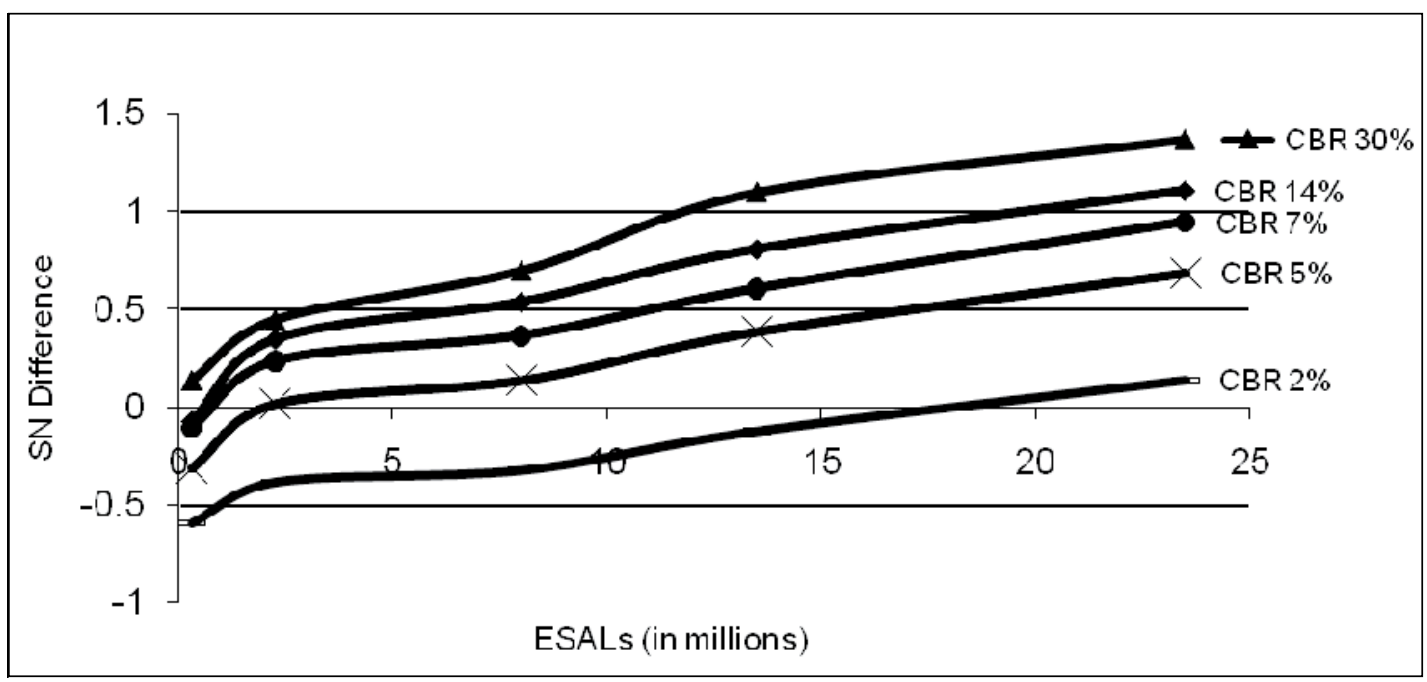

Figure 2 - SN Difference Vs ESALs 


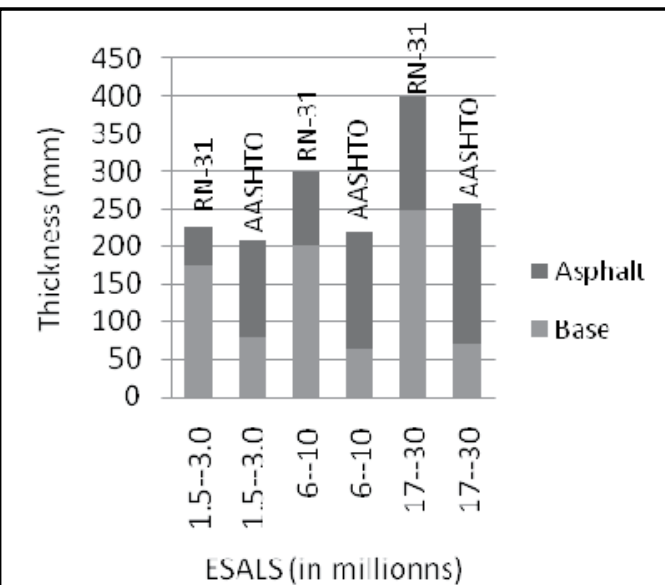

Figure 3 - Layer thickness with traffic load

It can be clearly seen that RN 31 gives a higher overall pavement thickness while AASHTO gives thicker asphalt layer and thinner base layer for all ESALs categories.

Fig 4 shows that the subbase layer thickness variation with subgrade CBR value for different ESALs.

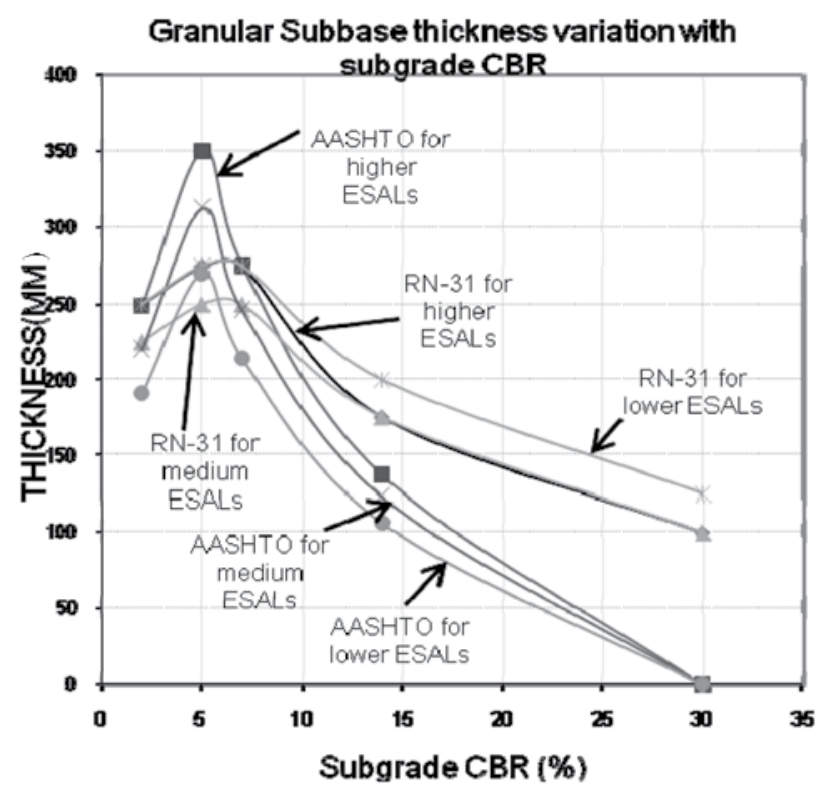

Figure 4 - Subbase thickness for lower load

The required subbase thickness is highest at a subgrade CBR of around 6\% for both design guidelines, and subbase thickness decreases as the subgrade CBR increases. Subbase is constructed directly on top of subgrade and weak subgrade is compensated with thicker subbase layer.

AASHTO design shows higher sensitivity for ESALs, compared with the RN-31. The required layer thickness should be increased with the ESALs in order to protect the subgrade due to cumulative damage. However RN 31 design shows the same layer thickness for medium and higher ESALs with subgrade CBR of $15 \%$ and above, and for medium and lower ESALs with subgrade CBR of $7 \%$ and below. So, the sensitivity of subbase for ESAL and CBR is very low in RN 31 and maintain a uniform thickness of subbase irrespective of subgrade CBR and ESALs.

\section{Evaluating the field performance of the pavement designs}

The experimental work was carried out in order to evaluate the pavement response for vehicle load. Field test was conducted on fairly good subgrade (CBR-25\%).

To verify the Finite Element Model, the design for lower and higher ESALs was selected to get an identifiable difference. Pavement design details for lower and higher ESALs categories are given in Table 2.

Table 2- Designed pavement data for test specimens.

\begin{tabular}{|c|c|c|c|c|}
\hline $\begin{array}{c}\text { Test } \\
\text { number }\end{array}$ & 01 & 04 & 02 & 03 \\
\hline $\begin{array}{l}\text { Design } \\
\text { Guideline }\end{array}$ & RN 31 & $\begin{array}{l}\text { AAS } \\
\text { HTO }\end{array}$ & RN 31 & $\begin{array}{l}\text { AAS } \\
\text { HTO }\end{array}$ \\
\hline $\begin{array}{c}\text { Traffic in } \\
\text { ESALs } \\
\text { (millions) }\end{array}$ & $1.5-3.0$ & $1.5-3.0$ & $17-30$ & $17-30$ \\
\hline $\begin{array}{c}\text { Layer } \\
\text { type - } \\
\text { Thickness } \\
(\mathrm{mm})\end{array}$ & $\begin{array}{c}\text { BS-50 } \\
\text { GB-175 } \\
\text { GS-125 }\end{array}$ & $\begin{array}{l}\text { BS-127 } \\
\text { GB-55 }\end{array}$ & $\begin{array}{l}\text { BS-150 } \\
\text { GB-250 } \\
\text { GS-100 }\end{array}$ & $\begin{array}{l}\text { BS-186 } \\
\text { GB-72 }\end{array}$ \\
\hline $\begin{array}{c}\text { Structural } \\
\text { Number } \\
\text { (SN) }\end{array}$ & $\begin{array}{l}\text { BS-0.63 } \\
\text { GB-1.41 } \\
\text { GS-0.47 } \\
\end{array}$ & $\begin{array}{c}\text { BS-1.6 } \\
\text { GB-0.44 }\end{array}$ & $\begin{array}{c}\text { BS-1.89 } \\
\text { GB-2 } \\
\text { GS-0.38 }\end{array}$ & $\begin{array}{c}\text { BS-2.34 } \\
\text { GB-0.58 }\end{array}$ \\
\hline $\begin{array}{c}\text { Total } \\
\text { SN }\end{array}$ & 2.51 & 2.04 & 4.28 & 2.92 \\
\hline
\end{tabular}

\section{Abbreviations:}

BS - Bitument surface

GB - Granular road Base

GS - Granular sub base 


\section{Construction procedure of the field test:}

The Dynamic Cone Penetration test (DCP) test was conducted on the prepared subgrade, after removing the top soil up to 1 foot, to estimate the subgrade CBR value. The $D C P$ value in $\mathrm{mm} /$ blow was converted in to CBR using TRRL equation as given in equation 2 [1]. The average subgrade CBR value was $25 \%$.

$\log _{10}(\mathrm{CBR})=2.48-1.057 \times \log _{10}(\mathrm{~mm} / \mathrm{blow})$

The subbase and base layers were constructed on prepared subgrade as shown in fig 5 .

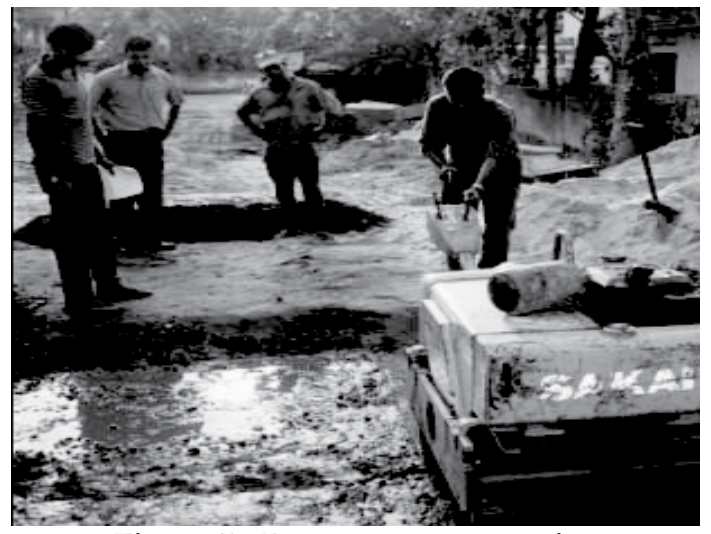

Figure 5 - Pavement construction
The material properties of the Base and Subbase complied with Standard Specification of Construction and Maintenance (SSCM) for road and Bridges in Sri Lanka and the CBR of subbase and base were $30 \%$ and $80 \%$, respectively. Prime coat was applied to ensure the proper bonding between asphalt and base layer and seals all voids in the surface of the base layer [9].

(2) The plate load test was conducted as shown in Fig. 6, to measure the pavement deflection for static load with different magnitude to simulate the response for vehicle loading.

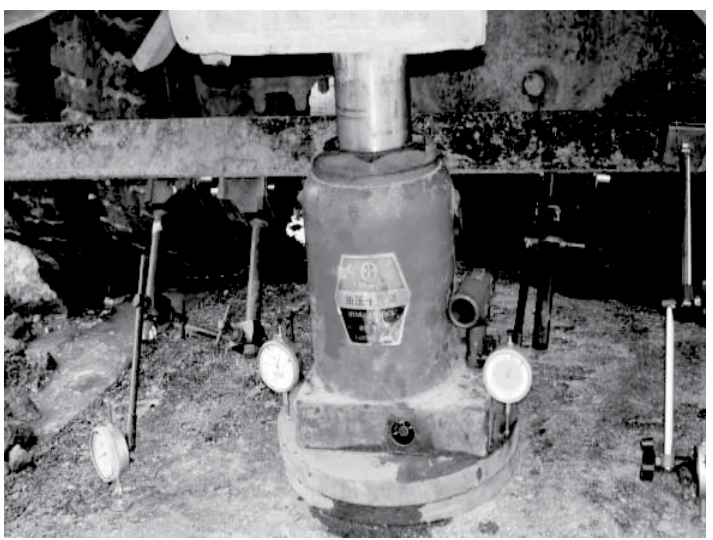

Figure 6 - Plate load test

Two dial gauges were placed on the plate in order to take the average deflection of the plate as shown in fig 6, while another two dial gauges were used on top of asphalt, closer to the plate in order to consider the uplift effect of the pavement due to the loading. Fig. 7 shows the constructed pavement sections.

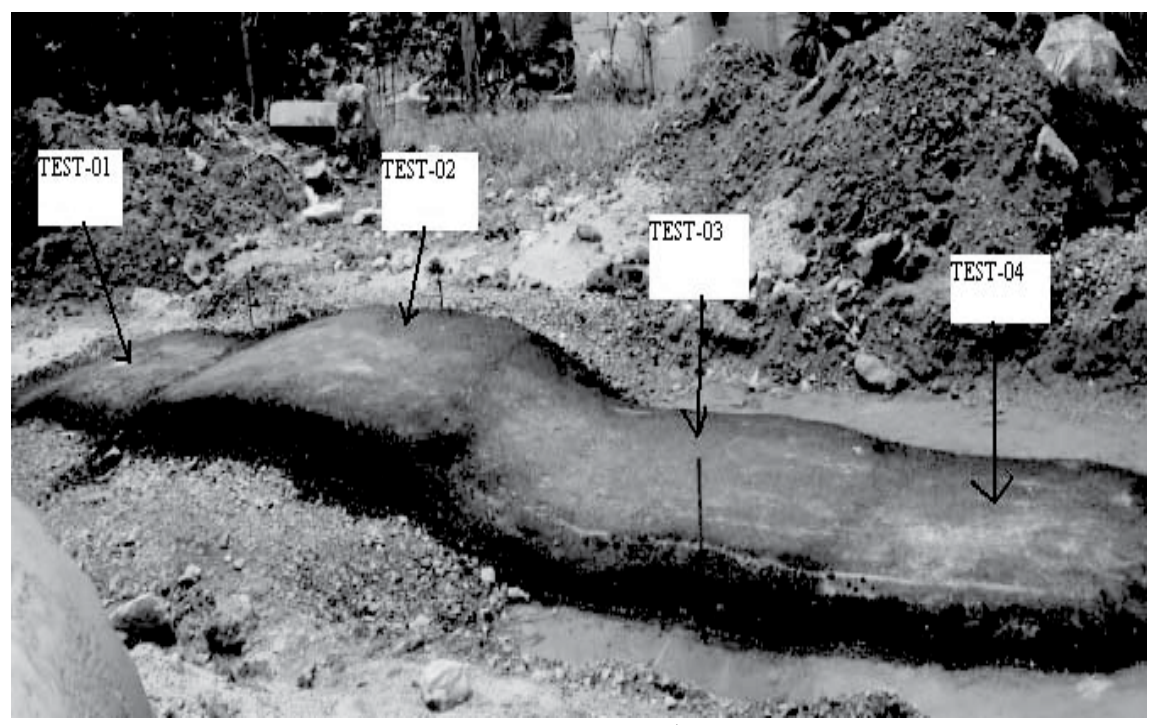

Figure 7 - Constructed pavement 
Table 3- Plate load test results.

\begin{tabular}{|c|c|c|c|}
\hline $\begin{array}{c}\text { Test } \\
\text { Number }\end{array}$ & $\begin{array}{c}\text { Design } \\
\text { method }\end{array}$ & $\begin{array}{c}\text { Load } \\
\text { (Ton) }\end{array}$ & $\begin{array}{c}\text { Deflection } \\
\text { (mm) }\end{array}$ \\
\hline 1 & RN 31 & \multicolumn{2}{|c|}{$\begin{array}{c}\text { Results were not } \\
\text { Found. }\end{array}$} \\
\hline 2 & RN 31 & 0 & 0 \\
\hline & & 1 & 0.33 \\
\hline & & 2 & 0.61 \\
\hline & & 3 & 0.87 \\
\hline & & 3.78 & 1.13 \\
\hline 3 & AASHTO & 0 & 0 \\
\hline & & 1 & 0.30 \\
\hline & & 2 & 0.53 \\
\hline & & 3 & 0.75 \\
\hline & & 4 & 0.93 \\
\hline 4 & AASHTO & 0 & 0 \\
\hline & & 1 & 0.30 \\
\hline & & 2 & 0.58 \\
\hline & & 3 & 0.90 \\
\hline & & 3.4 & 1.17 \\
\hline
\end{tabular}

Plate load test results are shown in table 3.

\section{Finite Element Modelling}

The SAP-2000 3D-Finite Element Software (FEM) was used to model the pavement test sections. Eight nodes isoparametric element was used for the finite element model. The mesh used in the analysis was finer at the contact zone [6] where higher accuracy of deflection is expected. Fig. 8 shows the finite elements mesh for a pavement section. A fine mesh was used at the loaded area and top most layers where effect of loading is more significant.

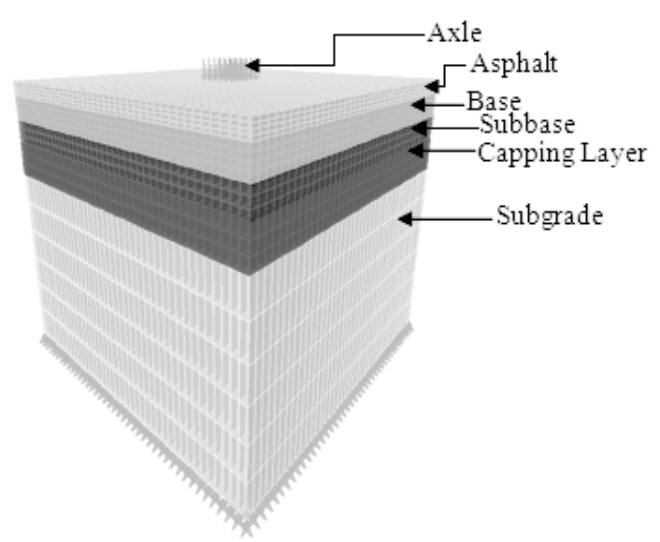

Figure 8 - FEM mesh arrangement
The normal contact pressure was assumed to be uniformly distributed over the contact area. The maximum load applied is four ton for $300 \mathrm{~mm}$ diameter area. This simulates the typical load applied by a typical truck tire under normal condition. All pavement sections were modeled as semi-infinite linear elastic system consisting of four layers; wearing, base course, granular sub-base and sub-grade.

The CBR value was converted into resilient modulus using the following empirical correlation specified in AASHTO (2002) design guideline:

$$
\mathrm{M}_{\mathrm{r}}=2555 \times(\mathrm{CBR})^{0.64 \ldots}
$$

Table-4 shows the material properties of FE model.

Table 4 - Material properties [18]

\begin{tabular}{|c|c|c|c|}
\hline \multirow{2}{*}{ Layer } & $\begin{array}{c}\text { CBR } \\
\text { (\%) }\end{array}$ & $\begin{array}{c}\text { Resilient } \\
\text { modulus } \\
\text { (Mpa) }\end{array}$ & $\begin{array}{c}\text { Poisson } \\
\text { ratio }\end{array}$ \\
\hline Asphalt & - & 3000 & 0.30 \\
\hline Base & 80 & 350 & 0.35 \\
\hline Subbase & 30 & 155 & 0.4 \\
\hline Capping & 8 & 66.7 & 0.45 \\
\hline \multirow{3}{*}{ Subgrade } & 2 & 27.9 & 0.45 \\
\cline { 2 - 4 } & 5 & 48.9 & 0.45 \\
\cline { 2 - 4 } & 14 & 95.4 & 0.45 \\
\cline { 2 - 4 } & 30 & 155 & 0.45 \\
\hline
\end{tabular}

\section{Results and discussion}

\subsection{The verification of finite element model with the field test.}

The 3D FEM results were verified with the field data to ensure the reliability of the finite element model [12]. Fig. 9 shows the deflection vs load graph for field test and FEM data.

The deflection data collected from field test was used to verify the FEM model. The model results show a good comparison with field data. The field data shows that deflection data of test-02, test-04 and test-03 were in descending order up to 2 ton. The same behavior is visible in field graph and FEM graph as shown in Fig 9. Load exceeding 3 ton, field test-04 shows higher deflection due to the failure of pavement as it was designed for the lower ESALs. 
Each layer in the pavement has been modeled using the elastic modulus and poison ratio. Plasticity characteristics and failure criteria of materials were not considered in the model. This may be the reason for higher deflection data beyond 2 ton load in test 04 .

There is a considerable difference between the magnitude of the deflection in the model and the field data. The discrepancies of the above results could be explained due to limitation of the software. SAP-2000 only facilitate linear element and does not consider in-elastic behavior of the material property. The closer answer could be achieved using Abaqus [1] numerical software where quadratic reduced integrated element is available.

The FEM model considered material as elastic and isotropic. Further, all the layers are infinite horizontally and subgrade is infinite both horizontally and vertically. It is not possible to model with large dimensions with very fine mesh, since it consumes significant time in analyzing. These limitations might have caused the considerable variation in the magnitude of the deflection results of the FEM and the field data. However deflection pattern of both FEM and field data showed a fairly good match. Therefore, the model can be effectively used for comparison of guidelines. The mesh type, the element type and the dimensions and material properties were identical in all the comparisons.
Table 5 shows the summary of the deflections and $\mathrm{SN}$ for the test sections.

Table 5- SN Vs Deflection

\begin{tabular}{|c|c|c|c|c|c|}
\hline Test & $\begin{array}{c}\text { Guide } \\
\text { line }\end{array}$ & $\begin{array}{c}\text { ESAL } \\
(\mathbf{m n})\end{array}$ & $\mathbf{S N}$ & $\begin{array}{c}\text { Defl'n } \\
\text { at } \mathbf{4} \text { ton } \\
\mathbf{( m m}\end{array}$ & $\begin{array}{c}\text { Defl'n } \\
\text { at } \mathbf{2} \text { ton } \\
(\mathbf{m m})\end{array}$ \\
\hline 02 & RN-31 & $17-30$ & 4.28 & 0.6 & 0.39 \\
\hline 03 & $\begin{array}{c}\text { AASH } \\
\text { TO }\end{array}$ & $17-30$ & 2.92 & 0.49 & 0.3 \\
\hline 04 & $\begin{array}{c}\text { AASH } \\
\text { TO }\end{array}$ & $1.5-3$ & 2.04 & 0.55 & 0.33 \\
\hline
\end{tabular}

A comparison of RN-31 and AASHTO designs were carried out using the above verified FEM. Deflection results of the pavement designs for deferent ESALs and subgrade categories are shown in Table 6.

\subsection{Analysis of different designs using FE Model for Local roads.}

Table 6 shows the computed deflections values for different designs. Same mesh type and size (block area) has been considered in order to maintain consistency of computed values and facilitate for comparisons. Favorable designs or guidelines can be selected on the basis of lower deflection induced at the base and subgrade levels.

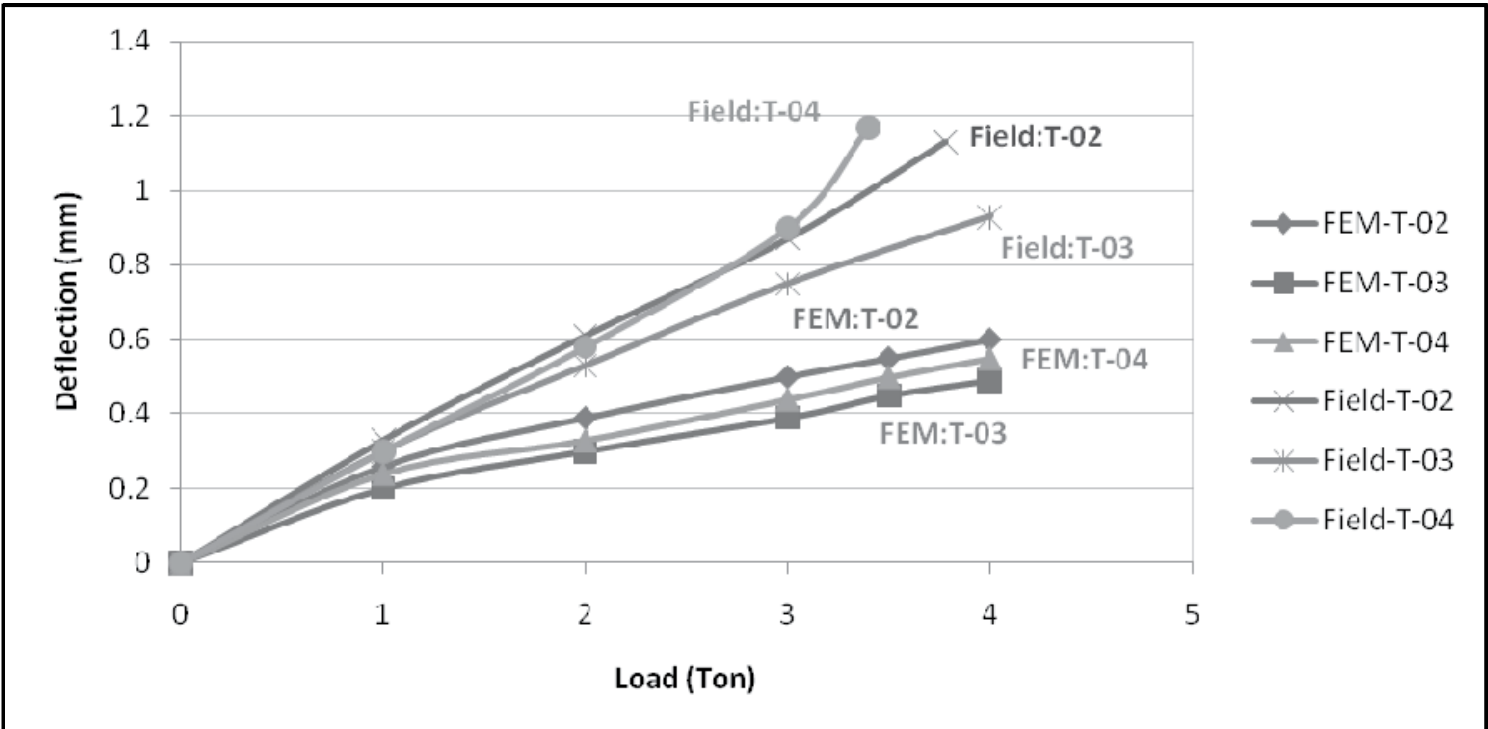

Figure 9 - Deflection vs load 
Table 6 - FEM results

\begin{tabular}{|c|c|c|c|c|c|c|c|c|c|c|c|}
\hline \multirow[b]{2}{*}{$\begin{array}{c}\text { Sub- } \\
\text { grade } \\
\text { CBR } \\
(\%)\end{array}$} & \multirow[b]{2}{*}{$\begin{array}{c}\text { ESALs } \\
\text { (mn) }\end{array}$} & \multicolumn{5}{|c|}{ RN-31 } & \multicolumn{5}{|c|}{ AASHTO } \\
\hline & & $\begin{array}{l}\text { Total } \\
\text { pave. } \\
\text { thick- } \\
\text {-ness } \\
(\mathrm{mm})\end{array}$ & $\begin{array}{l}\text { Tot. } \\
\text { SN }\end{array}$ & $\begin{array}{c}\text { Deflection } \\
\text { at top of } \\
\text { Asphalt } \\
(\mathrm{mm})\end{array}$ & $\begin{array}{c}\text { Deflection } \\
\text { at top of } \\
\text { Base } \\
(\mathrm{mm})\end{array}$ & $\begin{array}{c}\text { Deflection } \\
\text { at top of } \\
\text { Subgrade } \\
(\mathrm{mm})\end{array}$ & $\begin{array}{l}\text { Tot. } \\
\text { pave. } \\
\text { Thick. } \\
(\mathrm{mm})\end{array}$ & $\begin{array}{l}\text { Tot. } \\
\text { SN }\end{array}$ & $\begin{array}{c}\text { Deflection } \\
\text { at top of } \\
\text { Asphalt } \\
(\mathrm{mm})\end{array}$ & $\begin{array}{l}\text { Deflection } \\
\text { at top of } \\
\text { Base } \\
(\mathrm{mm})\end{array}$ & $\begin{array}{c}\text { Deflection } \\
\text { at top of } \\
\text { Subgrade } \\
(\mathrm{mm})\end{array}$ \\
\hline \multirow{3}{*}{2} & $\begin{array}{l}\text { Lower } \\
(1.5-3)\end{array}$ & 775 & 3.31 & 2.51 & 2.51 & 2.16 & 1270 & 3.69 & 3.53 & 3.53 & 2.75 \\
\hline & $\begin{array}{l}\text { Medium } \\
(6-10)\end{array}$ & 900 & 4.36 & 2.58 & 2.58 & 2.22 & 1430 & 4.58 & 3.61 & 3.61 & 2.89 \\
\hline & $\begin{array}{l}\text { Higher } \\
(17-30)\end{array}$ & 1000 & 5.23 & 2.65 & 2.65 & 2.31 & 1625 & 5.09 & 4.09 & 4.09 & 3.14 \\
\hline & & & & & & & & & & & \\
\hline \multirow{3}{*}{5} & Lower & 500 & 3.07 & 1.34 & 1.34 & 1.17 & 480 & 3.05 & 1.31 & 1.31 & 1.18 \\
\hline & Medium & 575 & 4.07 & 1.32 & 1.32 & 1.18 & 535 & 3.81 & 1.36 & 1.35 & 1.20 \\
\hline & Higher & 675 & 4.94 & 1.35 & 1.35 & 1.21 & 610 & 4.25 & 1.38 & 1.38 & 1.24 \\
\hline & & & & & & & & & & & \\
\hline \multirow{3}{*}{14} & Lower & 425 & 2.80 & 0.77 & 0.77 & 0.64 & 315 & 2.45 & 0.67 & 0.67 & 0.61 \\
\hline & Medium & 500 & 3.75 & 0.74 & 0.74 & 0.63 & 345 & 3.08 & 0.67 & 0.67 & 0.61 \\
\hline & Higher & 575 & 4.56 & 0.74 & 0.74 & 0.64 & 395 & 3.45 & 0.68 & 0.67 & 0.61 \\
\hline & & & & & & & & & & & \\
\hline \multirow{3}{*}{30} & Lower & 350 & 2.5 & 0.51 & 0.51 & 0.41 & 207 & 2.05 & 0.41 & 0.41 & 0.39 \\
\hline & Medium & 425 & 3.5 & 0.49 & 0.49 & 0.40 & 220 & 2.6 & 0.40 & 0.40 & 0.38 \\
\hline & Higher & 500 & 4.3 & 0.48 & 0.47 & 0.40 & 258 & 2.93 & 0.39 & 0.39 & 0.37 \\
\hline
\end{tabular}

Chazallon et al [3] reported clearly that higher attention needs to be given to the vertical stress which mainly causes rutting failure. Since it is questionable whether the rutting or the bending stress of the pavement is vital, if bending stress is beyond the threshold value and the vertical stress is within the limit then the fatigue type failure will become crucial. The authors have given the attention on vertical deflection which cause rutting and have not considered any threshold criteria for comparison.

Computed results in table 6 shows that surface deflection (total deflection of all the layers) of the pavements on weak subgrade (CBR $2 \%$ or less) which have been designed according to AASHTO guidelines is higher than that of the RN 31 for all traffic categories. Further, deflection at the subgrade level is significantly higher because low pavement thickness in AASHTO design induces higher vertical stresses at the subgrade level.
Both AASHTO and RN 31 design for CBR 5\% provide the similar deflection at subgrade and base level. Still the deflections of the RN 31 design are less than that of AASHTO Designs.

AASHTO design for the CBR $14 \%$ and CBR 30 $\%$ shows that deflection at the subgrade and base level is low compared with the RN 31. It can be seen that the deflection at the base level is high in RN 31 and it contributed significantly for the difference. This has been revealed in a recent study that the rutting takes place mainly in base and subbase, when the bearing capacity of soil is sufficient [4]. For subgrade CBR of $14 \%$ and $30 \%$, the deflection at base level [3] is high in RN 31 even though the both RN 31 and AASHTO have shown similar deflection at subgrade level. It is obvious that the stress at base level will reduce with the thick asphalt layer used in AASHTO design. 


\section{Conclusions}

From the results, in particular, the following conclusions can be made:

i. The comparison of AASHTO and RN 31 guidelines shows that RN 31 gives lower $\mathrm{SN}$ for Lower ESAL categories and higher $\mathrm{SN}$ for higher ESALs categories. The SN difference (RN:31-AASHTO) increases as the subgrade CBR increases.

ii. RN 31 gives a higher overall pavement thickness except CBR $2 \%$ and AASHTO gives thicker asphalt layer and thinner base layer for all ESALs categories

iii. Asphalt and base material thicknesses do not show any response for subgrade strength which is measured in the form CBR.

iv. Lower CBR of the subgrade is compensated with subbase layer in both design guidelines. The sensitivity of subbase thickness for ESALs and CBR is less in RN 31.

v. For all ESAL categories, RN 31 design for CBR $5 \%$ or below has shown lower deflection than that of AASHTO designs. So RN 31 is the preferred guideline for subgrade CBR of $5 \%$ or below (RN-31 considered the range of subgrade $\mathrm{CBR}$ value, so authors considered average value of $\mathrm{CBR}, 5 \%$ covered up to $7 \%$ ).

vi. For all ESAL categories, AASHTO design for stronger foundation (CBR $14 \%$ and above) have shown lower deflection than that of RN 31 design. So AASHTO is the preferred guideline for subgrade CBR of $14 \%$ and above. (Avg. CBR-14\% covered from $8 \%$ )

\section{References:}

1. ABAQUS. Theory manual, Habbit, Karlson \& Sorenson, Inc. 2005.

2. AASHTO. AASHTO Guide for Design of Pavement Structures. Washington, DC: American association of state highway and transportation officials. 1993.

3. Chazallon C, Koval G, Hornych P, Allov F, Mouhoubi S.,Modelling of rutting of two flexible pavements with the shakedown theory and the Finite Element Method. Elsevier Journal of Computer and Geotechnics 2009; 36:798-809.
4. COST 337. Unbound granular materials for road pavements. European Commission Edition. Final Report: 2003.

5. Fang H, Haddock J.E, White T.D, Hand A.J., On the characterization of flexible pavement rutting using creep mode-based finite element analysis. Elsevier Journal of Finite element analysis and design 2004;41(1):49-73.

6. H.Akbulut, K. Aslantas. Finite element analysis of stress distribution on bituminous pavement and failure mechanism. Elsevier Journal of Materials and Design, 26, 2005: 383-387.

7. Huang Yang. H., NOV. Pavement Analysis and Design. 2 nd ed. USA: Pearson prentice hall; 2003. P. 505-528.

8. Hartman A.M. An experimental investigation into the mechanical performance and structural integrity of bituminous road pavement mixtures under the action of fatigue load conditions. $\mathrm{PhD}$ Thesis. Department of Mechanical Engineering, University College Dublin, Ireland; 2000.

9. Lavin Patrick G. Asphalt pavements. London: Spon press; 2003.

10. Lay MG., Handbook of road technology. Planning and pavements, vol. 1. New York: Gordon and Breach Science Publishers; 1990. p. 277-92.

11. Martin A.M., Owende P.M.O., O'Mahony M.J., Ward S.M., A timber extraction method based on pavement serviceability and forest inventory data. Forest Sci, 2000; 46(1):76-85.

12. Mulungye R.M., Owende P.M.O., Mellon K., Finite element modelling of flexible pavements on soft soil subgrades. Elsevier Journal of Materials and Designs, 28, 2007: 709-756.

13. Owende P.M.O., Hartman A.M., Ward S.M., Gilchrist M.D., O'Mahony M.J., Minimizing distress on flexible pavements using variable tyre pressure. I Transport Eng ASCE 2001;127(3):254-62.

14. Sherwood P.T. Alternative material in road construction. London: Thomas telford publications. 1995.

15. Transport and Road Research Laboratory. Road Note-31: A guide to the structural Design of Bitumen-surfaced roads in tropical and subtropical countries. 3rdedition. London: Her Majesty's Stationery office. 1977.

16. Transport Research Laboratory. Overseas Road Note-31: A guide to the structural Design of Bitumen-surfaced roads in tropical and subtropical countries. $4^{\text {th }}$ edition. London: Overseas Development Administration. 1993. 
17. TRL. Normalisation of measured distresses on European road pavements. PARIS/WPIII/01/ Final Report, TRL, Crowthorne, England; 1997.

18. Ullidtz P. Pavement analysis. Amsterdam: Elsevier science Publishers B.V. 1987.

19. Yoder E.J., Witczak M.W., Principles of pavement design. $2^{\text {nd }}$ edition. USA: John wiley and sons, Inc; 1975. P.03-21.

20. Zakaria M., Lees Z., Rutting characteristics of unbounded aggregate layers. Elsevier Journal of Construction and Building Materials, 1993;10 (3):185-189.

\section{Acknowledgement.}

The authors wish to thank Mr. R.W.M.U.R.B Gandarawatta and Miss. R.W.Gunasekara for their help on experimental work. And Mrs. Sriyani Abeywickrama, Director (Western Road Projects, Sri Lanka) and CML construction Ltd for providing all the equipments and materials which were required for the field verifications.

\section{Symbols:}

$W_{18}$-18-kips equivalent single axle load

$Z_{R}$-Reliability (Z-statics from the standard normal curve)

$S_{0} \quad$-Overall standard deviation of traffic

$\mathrm{SN}$ - Structural number

$\Delta$ PSI-Loss in serviceability from the time the pavement is new until it reaches its TSI.

$\mathrm{M}_{\mathrm{R}}$-Soil resilient modulus of subgrade in $\mathrm{lb} /$ inch $^{2}$

Appendix:
$\log W_{18}=Z_{R} \times S_{0}+9.36 \log (S N+1)-0.20+\frac{\log \left(\frac{\Delta P S I}{4.2-1.5}\right)}{0.40+\frac{1094}{(S N+1)^{5.19}}}+2.32 \log \left(M_{R}\right)-8.07$

(AASHTO 1993 [2]) 